\title{
ALUSIONES GEOGRÁFICAS EN TÉRMINOS DE LA TÉCNICA Y DEL MERCADO
}

La técnica y el mercado tienen particulares exigencias expresivas ${ }^{1}$; su terminología persigue de ordinario finalidades publicitarias. Las imágenes expresadas por los términos tienden a menudo a seducir al comprador. Uno de esos expedientes expresivos consiste, como es sabido, en la alusión a la proveniencia - real o presunta- del producto o de la mercancía desde tierras lejanas.

La terminología alfarera ofrece ejemplos muy antiguos e instructivos de este tipo de denominación de valor geográfico. A veces, para designar determinado tipo de objeto de barro se recurre a un término geográfico usado tal cual, con función de sustantivo común.

De las regiones del Mediterráneo oriental se puede aducir el conocido ejemplo del término técnico ќ́paros 'vasija de barro', idéntico al topónimo Képauos en Caria; es, pues, un término alusivo a la verdadera o presunta zona anatólica de fabricación del producto. Adoptado por las diversas lenguas de cultura, el término prehelénico

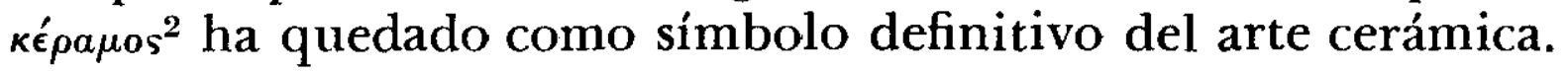

Las regiones de la vertiente occidental del Mediterráneo ofrecen el ejemplo, no menos instructivo, del nombre de recipiente o b b a 'poculi genus uel ligneum uel ex sparto', idéntico al topónimo $\mathrm{O} \mathrm{b} \mathrm{b} \mathrm{a}{ }^{3}$, en Mauretania, de modo que cabe la posibilidad de inter$87-105$.

1 Véase mi artículo "Esigenze espressive del mercato", VoxR, V, 1940, págs.

2 Atribuído a la tradición prehelénica en su aspecto anatólico por P. KRETschmer en Glotta, pág. 284 (cf. también P. Chantraine, La formation des mots en grec ancien, Paris, 1933, pág. 133: "le mot appartient au vocabulaire d'une technique développée dans le monde méditerranéen"; J. B. HofmanN en $L E W^{3}$, I, pág. 287; Etymol. Wörterb. d. Griech., 1950, pág. 139), el término técnico ќ́ barro cocido', podía asumir en el uso regional chipriota el de 'edificio carcelario construído con ladrillos de barro cocido', a juzgar por el escolio oi yù

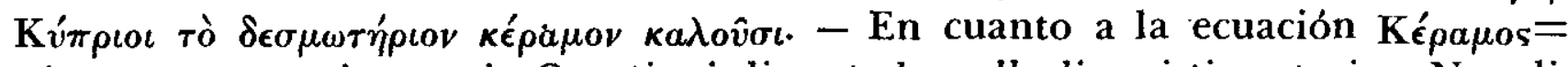

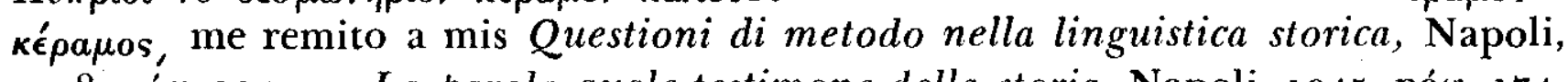
1938, pág. 235, y a La parola quale testimone della storia, Napoli, 1945, pág. 174 .

${ }^{3}$ Cf. M. Niedermann en $L E W$, pág. 533 , y J. B. Hofmann en $L E W^{3}$, II, 
pretar también esta relación entre sustantivo común y topónimo en el marco histórico de una técnica regional de recipientes exportados a la Europa mediterránea occidental desde el Âfrica del Norte*

Así, pues, en los dos casos el nombre de lugar, Képapos y O b b a, se ha adoptado sin ningún procedimiento de derivación para expresar

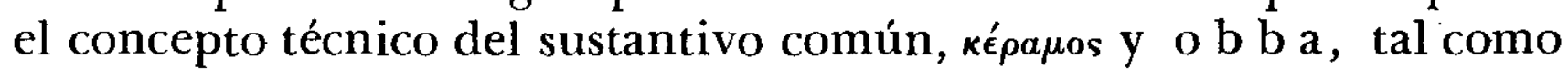
en época menos remota el nombre de la ciudad de Faenza, célebre a fines de la Edad Media por sus fábricas de objètos de barro coloreados de manera original y con gusto exquisito, ha dado el nombre francés faïence a esta especialidad de la alfarería italiana exportada a Francia ${ }^{5}$.

El TÉrmino técnico s e ri a (s e r i o la) 'uas fictile' empleado PARA CONSERVAR EL VINO

Todos estos hechos son en gran parte conocidos. Pero lo que no se ha hecho notar hasta ahora es que el nombre de vasija s e ria (s e r i o la), atestiguado desde Plauto, pertenece con toda probabilidad a la misma categoría de términos de la técnica alfarera, transformados en términos de mercado y alusivos a la verdadera o presunta tierra de origen.

Los diccionarios etimológicos latinos más recientes coinciden en considerar el nombre s e ri a como vocablo de origen desconocido. Ernout se inclina a atribuir el término a la tradición paleomediterránea ("sans doute emprunté à une langue méditerranéenne"). Hofmann define s e r i a "vocablo exótico tomado por el latín de una fuente desconocida', acogiendo sin embargo, por vía de hipótesis, la opinión de Ernout en cuanto al origen mediterráneo ${ }^{6}$. En suma, los dos diccionarios etimológicos latinos más recientes y autorizados concuerdan en proponer para s e ria (s e riola) la siguiente definición: supervivencia, en el latín, de una tradición indígena del Mediterráneo.

pág. 194; véase también mi artículo "La Iberia en el sustrato étnico-lingüístico del Mediterráneo occidental”, NRFH, I, 1947, pág. 129.

" El hecho de qưe en el uso dialectal bereber el nombre del esparto, tsennît, haya pasado a designar un 'cesto de esparto usado en la pesca', llamado también asennaz (Destaing, Dictionnaire français-berbère, dial. des Beni-snous, Paris, 1914, págs. 77 y 238; cf. también Museum Helveticum, II, 1948, págs. 80-81), no habla ciertamente en contra de esta interpretación, puesto que confirma una característica de la cultura regional africana que consiste en la manufactura de artículos tejidos de esparto.

5 "Non si sono mai avvisati i Faentini di chiamar la loro maiolica faenza (in quanto fabbricata in Faenza), benchè fayence la chiamino i Francesi”, dice el conde Lorenzo Magalotti, Lettere familiari, XVI; cf. también FEW, III (1934), pág. 366 .

${ }^{6}$ Cf. Hofmann en $L E W^{3}$, II, págs. 520-521; Ernout-Meillet, Dictionnaire étymologique de la langue latine, II (1951), pág. 1089. 
Ahora bien, hasta ahora no se ha prestado atención al comentario etimológico que ofrecen las fuentes latinas al término técnico c i i i c i a en cuanto incluye también el nombre s e ria, interpretados uno y otro como sustantivos de valor geográfico y, como tales, idénticos a los topónimos $\mathrm{C}$ ili i i a y $\mathrm{S}$ y ria. He aquí el texto preciso: "s e riola (syriola) uas fictile uini apud Syria m primum excogitatum, sicut $\mathrm{c}$ ili $\mathrm{c}$ i a $\mathrm{a}$ Cili $\mathrm{c}$ i a nuncupata, unde primum aduectae sunt" ?. Así como el término técnico cili c i a

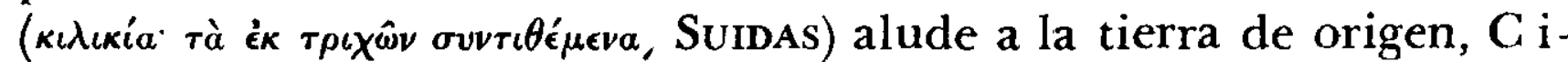

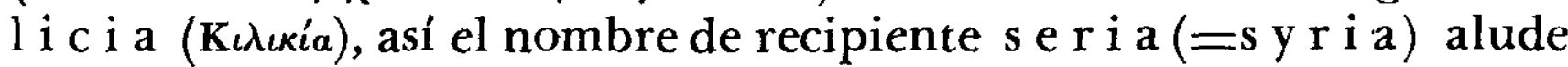
a S y ria, verdadera o presunta tierra de exportación.

El caso no es único. En efecto, para denominar drogas exóticas o productos agrícolas importados de regiones lejanas, la lengua del mercado recurre no pocas veces a $\mathrm{S}$ y $\mathrm{r}$ i a. Por ejemplo, los griegos conocían una especie de bejuco originaria de Siria y otra de Cilicia

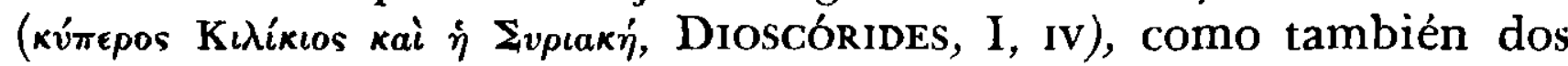
especies distintas de nardo, una de la India y otra de Siria $(\dot{\eta} \mu \grave{\varphi} v$

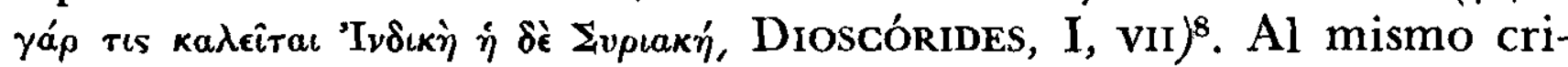
terio discriminador según el país de origen se atiende la terminología griega de muchas otras hierbas aromáticas y medicinales ${ }^{9}$. En la

"IsIDoro, Origines, XX, vi, 6; ThLL, Onomast., II, 439. Más rico de noticias es el testimonio de Varrón relativo a la cría de cabras en las zonas montañosas de Cilicia y Frigia, a su esquileo y a la elaboración del pelo caprino en artefactos textiles: "Tondentur caprae quod magnis uillis sunt, in magna parte Phrygiae; unde cilicia et cetera eius generis solent fieri; sed quod primum ea tonsura in Cilic i a sit instituta, nomen id... adiecisse dicunt" (De re rustica, II, $\mathrm{xI}$ ).

${ }^{8}$ El texto de Dioscórides, I, vir, continúa así, ofreciendo nuevos detalles

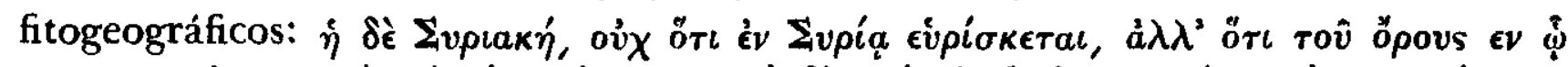

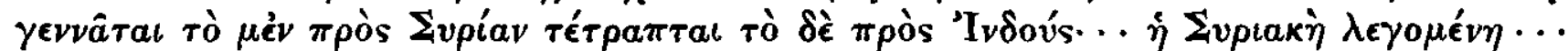

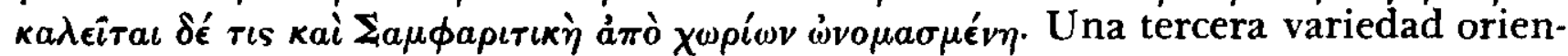
tal de nardo es la que conoce Dioscórides (I, IX) con el nombre de ópctì vápóos,

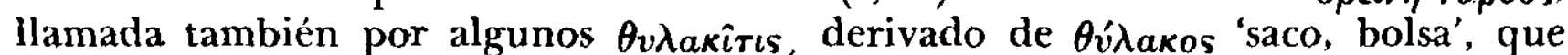

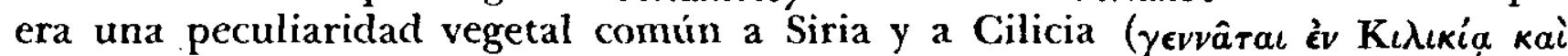
Supía). A las variedades orientales de nardo se oponía, siempre según Droscóki-

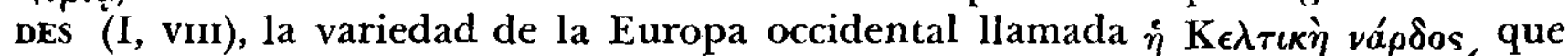

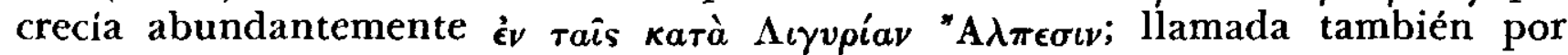
los habitantes, de acuerdo con el criterio fitogeográfico tradicional, oa (s a $l$ i u n c a Virgilio, Plinio, etc.), o sea 'hierba peculiar del territorio habitado

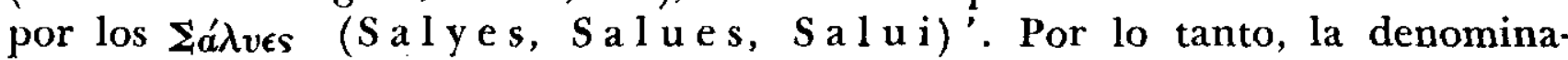
ción saliunca ha de atribuirse a las hablas paleoligures del montañoso territorio interior de las regiones de Masalia, pero el motivo fitogeográfico de la creación traiciona el modelo griego. - Sobre este particular podrán consultarse mis artículos en ARom, X, 1926, págs. 1-20, en Silloge linguistica Ascoli, págs. 495 y 526 y en La Parola del Passato, I, 1946, págs. 46 y sigs., y sobre todo mi libro Colonizzazioni nell'antico Mediterraneo occidentale alla luce degli aspetti linguistici, Napoli, 1950, págs. 82-83; cf. asimismo Hofmann en $L E W^{3}$, II (1951), pág. 469 .

- Las alusiones a Siria son muy frecuentes en Dioscórides: se distinguen varie- 
terminología latina no faltan alusiones análogas a Siria para plantas importadas y utilizadas en la economía doméstica. Baste recordar la $\mathrm{rad}$ i x $\mathrm{S}$ y ri a ca, nombre de una especie de rábano documentado en Columela (XI, HI, 16, 59), quien nos ofrece asimismo un precioso comentario sobre esa palabra: "quae Assyrio semine uenit" (X, CXIV) ${ }^{10}$. En Columela aparece igualmente la variante $S$ y ricus, que Leo Spitzer, con feliz intuición, ha relacionado ${ }^{11}$ con el it. sorgo y sus sinónimos dialectales sorg, sorghét Treviso, sorgati (pl.) Trentino ${ }^{12}$, sorg-turk Friuli, súreke Abruzzo, etc. ${ }^{13}$

Completan la serie de alusiones fitogeográficas a Siria los testimonios de los glosarios, que refieren el término $\mathrm{s} \mathrm{u} \mathrm{ri} \mathrm{a} \mathrm{c} \mathrm{a}\left(=\sigma v^{-}\right.$

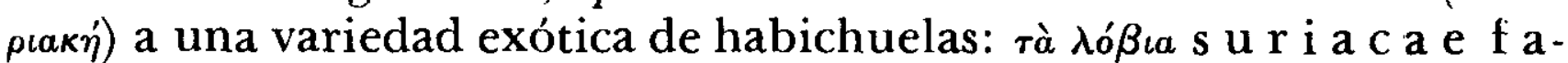
s i o 1 i (CGlLat, III, 265, 41), nombre fácil de reconocer en suriaca, suriacuni 'habichuela' en dialecto calabrés ${ }^{14}$.

Como se habrá visto, prevalece Siria, en unión sobre todo de la India y de Cilicia, en las denominaciones griegas o latinas de especies vegetales importadas en época antigua de tierras lejanas, mientras que en épocas más recientes es la India la que prevalece en las denomina-

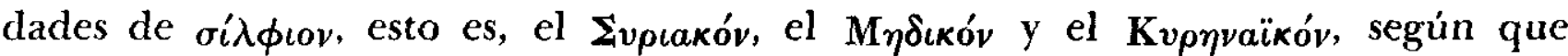

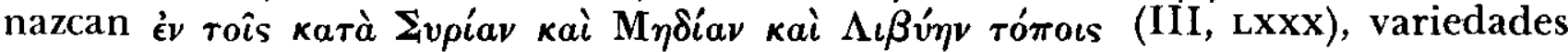

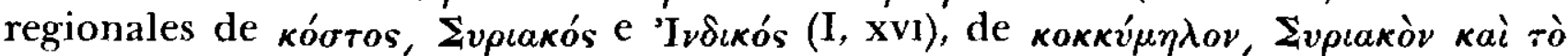

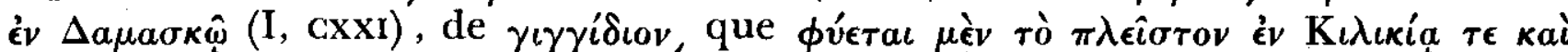

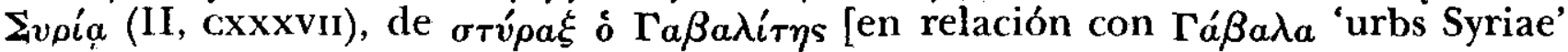

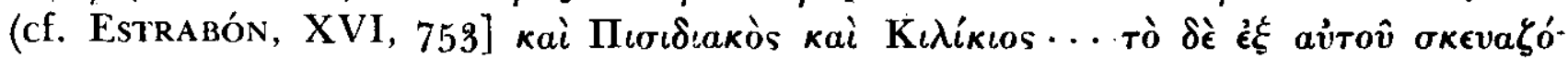

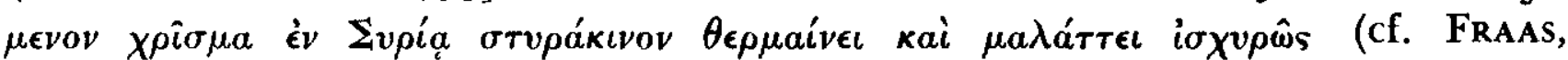
Synops. plant. flor. class., pág. 194; Heldreich, Nutzpflanzen Griechenlands, pág. 38; V. Hehn, Kulturpflanzen und Haustiere in ihrem Übergang aus Asien nach Griechenland, 8 a ed. con contribuciones de Schrader, ENGler y Pax,

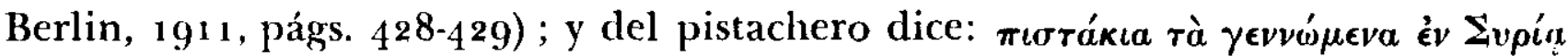
(I, cxxiv); véase también Plinio, XIII, LI: "S y $\mathrm{r}$ i a ... peculiares habet arbores, in nucum genere $\mathrm{p}$ i s t a c i a nota" (cf. V. HEHN, op. cit., págs. 422-423).

${ }^{10}$ Cf. Hehn, op. cit., pág. 501, y Schrader-Nehring, Reallex. indog. Altertumsk., vol. II, 1929, pág. $25^{1}$.

11 SpITzFr, "Die Namengebung bei neuen Kulturpflanzen im Französischen", $W S$, IV, 1914 , págs. $122-147$, sobre todo 140 y 146; véase $R E W^{3}, 8503$, y HofMANN en $L E W^{3}$, II (1952), pág. $63^{8}$ (S y ri a cus y Sy ricus, etc.)

12 C. G. Pedrotti, Le piante coltivate del Trentino e $i$ loro nomi dialettali, Trento, 1936, pág. 10

${ }^{13}$ Cf. O. Penzig, Flora popol. ital., vol. I, Genova, 1924, págs. $470-471$ y 530.

${ }^{14}$ Cif. Penzig, op. cit., vol. I, págs. $345-346$; en cuanto al término s u r i a -

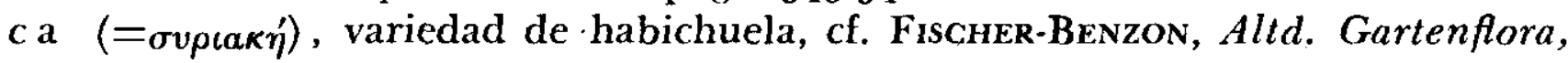
1894, pág. 98. Para la historia de los nombres de la habichuela alusivos a la proveniencia exótica de algunas variedades cultivadas en Italia, Francia y España, cf. VoxR, V, 1940, págs. 101-104. Respecto al nombre calabrés de una variedad de habichuela, cf. G. Rohlfs en $Z R P h, \mathrm{XL}, 1920$, pág. 340, y $R E W^{3}$, 8502 . 
ciones de productos agrícolas importados de América a Europa ${ }^{15}$; con la India rivalizan, en este sentido, España y Turquía ${ }^{16}$.

\section{EL TÉRMINO TÉCNICO ESP. zurriaga 'látigo'}

En el cuadro de historia de la agricultura europea esbozado en las páginas anteriores será lícito tal vez incluir el episodio representado por el término técnico zurriaga 'látigo' de la Península ibérica.

Pero antes de entrar en detalles acerca del problema, convendrá hacer una observación. El REW (8476a) presenta el esp. zurriaga en un contorno léxico bastante extraño. En efecto, al lado de este término y de su sinónimo portugués azorrague, se reúnen bajo el mismo rótulo onomatopéyico algunos verbos que expresan la idea de 'apalear' o de 'zurrar' en las lenguas peninsulares, junto con el nombre del abejorro sorla en dialecto tridentino y el nombre del trompo surla en triestino. Para completar esta familia de presuntas voces onomatopéyicas se citan además dos sustantivos: cat. surra 'paliza en las asentaderas' y el esp.-port. zorra; el primero es acogido en el seno de la familia, y el segundo es rechazado.

Sin embargo, habrá que hacer todavía más eliminaciones. Por ejemplo, el triest. surla 'trompo' no puede separarse del sinónimo vecino gurla, $-i$ Friuli, que junto con gurla Como y corlo Mantua 'trompo' forma parte de los reflejos dialectales de ${ }^{*} \mathrm{c}$ u rrul u s${ }^{17}$.

${ }^{15}$ Los tipos de denominación más conocidos de animales y productos agrícolas de origen americano alusivos a la India son: coq d'Inde, gallo d'India, gallorinnie, dindion, dindu, dindon, etc. para el 'pavo'; blé d'Inde, Indian corn, grano d'India, granudinnia, etc. para el 'maíz'; figuier d'Inde, fico d'India, ficurinnia, etc. para la 'tuna', etc.; cf. SPITzer, loc. cit., y V. Bertold, Questioni di metodo nella linguistica storica, págs. 119 y sigs., y "Esigenze espressive dẹ mercato", VoxR, V, 1940, págs. 97 y sigs.

${ }_{16}$ Al país de origen de determinado producto exótico suele sustituirse en la terminología del mercado la alusión al país que acoge por primera vez el artículo. Para los productos importados de América, es España la primera escala en el continente europeo, y así tenemos blé d'Espagne 'maíz', papas des Espagnols 'patata', figo d'Espagno 'tuna', etc.; cf. VoxR, loc. cit., págs. 99-105. - No menos frecuentes son las alusiones a Turquía: "Le maiz est semblable à ce grain que nous appelons... blé de Turquie" (Godefroy, s. v.), it. granturco "nome dovuto a un errore sull'origine della pianta, mantenuto forse dai fiocchi di peli che terminano le spighe del maïs che sarebbero stati paragonati alla barba dei Turchi, o pel vigore della pianta che motivava un' espressione analoga a quella di forte come un turco" (A. DE Candolle, L'origine delle piante coltivate, Milano, $\mathbf{1 8 8 3}$, pág. $5^{21}$ ), it. gallo di Turchia, etc. 'pavo', ingl. cock of Turkey y luego turkey, etc., donde Turquía es tomada por los hablantes como tierra lejana de exportación en general (cf. N. Maccarrone, "Le denominazioni del 'tacchino' e della 'tacchina' nelle lingue romanze", $A G I t$, XX, 1926, pág. 23).

${ }^{2 i}$ Cf. $R E W^{3}, 245^{b}$; A. Thomas, Mélanges d'étymologie française, 19o2, págs. 59-6o (fr. curle 'rouet qui sert à tordre le fil de caret', etc.); $F E W$, II, 2 a parte (1946), pág. 1575 . 
En el tipo triestino surla, el rasgo onomatopéyico aparece, pues, reducido a la sola modificación de la consonante inicial, es decir que tenemos ahí el lat. ${ }^{*} \mathrm{c}$ u r r u la, con fisonomía regional, retocado por un intento de imitar el ruido del trompo.

También surgen dudas en cuanto a la presunta naturaleza onomatopéyica del nombre sórla 'abejorro' en el dialecto tridentino. Ciertamente no habla en favor de esta hipótesis el área de difusión del nombre, que según datos recientes ( $A I S$, III, 471) comprende algunos valles alpinos aislados, Val di Non, Val di Sole, Val di Giudicarie, Valsugana, etc., avanzando al Sur hasta las riberas veronesas del Garda. El aislamiento geográfico de este tipo de denominación del abejorro hace pensar más bien en la hipótesis de un origen prelatino.

Por último, no sin razón se declaraba Meyer-Lübke en contra de la hipótesis de Sainéan, que también en el esp. zorra quería ver una creación de finalidad onomatopéyica. En efecto, no creo que fuera fácil encontrar, en la época antigua ni en la época moderna, apoyos y confirmaciones en la terminología de la zorra ${ }^{18}$.

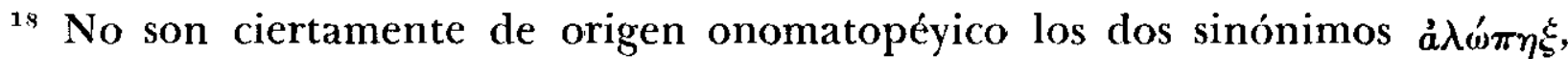

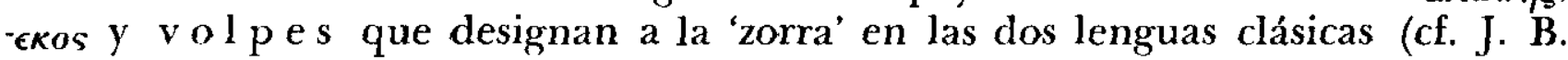
Hofmann, Etymol. Wörterb. des Griech., 1950, pág. 14; ERnout-Meillet, Dict. étym. de la langue lat., vol. II, 1951, pág. 1328); tampoco puede llamarse creación onomatopéyica el antiguo nombre de la zorra en las hablas indígenas

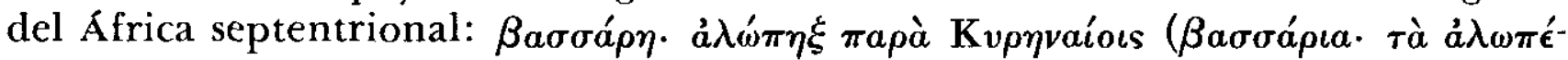

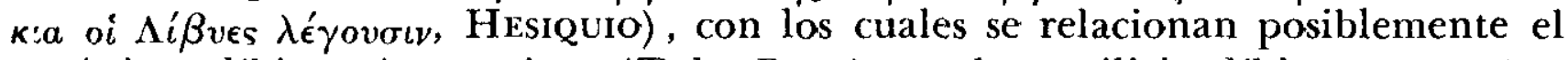
topónimo líbico Assaria (Tab. Peut.). y el gentilicio líbico 'A (Ptolomeo, IV, VI, 22), autorizando así la hipótesis de una consonante protética inicial. Este hecho no deja de tener alcance histórico, por cuanto da lugar a una comparación entre el copto ba ̌̌ ar 'zorra' y el vasc. ăsari azari etc. 'zorra', comparación ya hecha por Hugo Schuchard, "Baskisch-hamitische Wortvergleichungen", en RIEV, VII, 1913, pág. 21. Tenemos aquí uno de los casos más evidentes de concordancia, no desprovisto de valor histórico para la reconstrucción de las hablas indigenas de sustrato a lo largo de las regiones costeras africanas y europeas de la vertiente occidental del Mediterráneo (cf. sobre este particular mi artículo “Contatti e conflitti di lingue nell'antico Mediterraneo", $Z R P h$, LVII, 1937, págs. 144 y sigs.) . - Una intención metafórica, y no onomatopéyica, podría considerarse quizá como tema constante en que se inspiran ciertos nombres de la zorra en época antigua y moderna: la imagen de la astu-

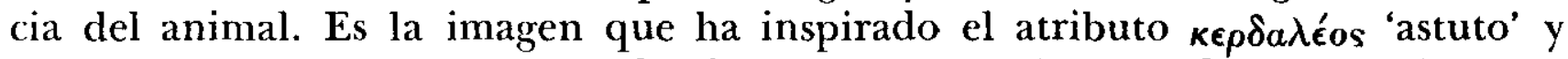

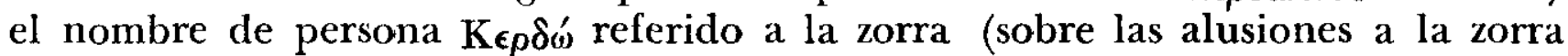
en Arquíloco, cf. Schrader-Nehring, Reallex. indog. Altertumsk., 1, 1923, pág.

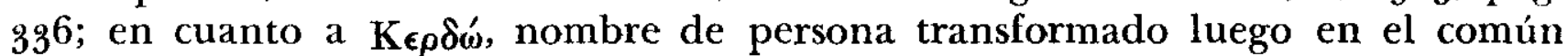
$\kappa \epsilon \rho \delta \omega ́$ 'zorra', cf. V. HeHN, Kulturpflanzen u. Haustiere, 8a ed., 1911, pág. 340, y E. Borsacq, Dict. étym. de la langue grecque, pág. 440) . - Con el tipo de deno-

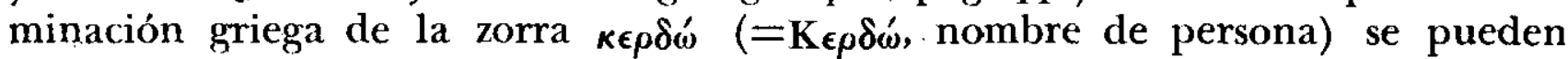
comparar los muchos casos de lenguas modernas como renard $=$ Renard, bastien = Bastien del francés, porque "quand on va à la chasse du renard, il ne faut pas prononcer le mot renard, on serait sûr de ne pas trouver cet animal. Quand on veut parler de lui, on l'appelle Bastien"; esp. pedro = Pedro, sardo 
Tampoco en lo que respecta a la historia de zurriaga se ha llegado a un pleno acuerdo de opiniones. Spitzer (y tras él MeyerLübke) ${ }^{19}$ explica el término simplemente por intento mimético, mientras Elcock ${ }^{20}$ prefiere admitir una relación no bien precisada entre zurriaga y lat. c o r rigia. Sólo que esta presunta relación no parece confirmada, como es fácil de ver, ni por los sonidos de la sílaba inicial ni por los elementos estructurales (-aga) de la palabra. Así, pues, el problema etimológico del término técnico zurriaga no puede darse por definitivamente resuelto; al contrario, es susceptible de nuevas investigaciones.

Conviene a este propósito recordar una importante noticia acerca de la técnica de los mangos de látigo: el árbol preferido era el "Celtis australis L.", denominado a menudo, por esa razón, el "árbol del látigo" por excelencia. La ciudad de Perpignan, en el Sur de Francia, era famosa por esa especialización técnica. "À Perpignan -nos dice E. Rolland en su Flore populaire, vol. X, pág. $95^{-}$on fait des manches de fouet de Celtis australis et divers ouvrages de menuiserie et de marqueterie" ${ }^{21}$. No debe sorprendernos, pues, que en el uso provenzal el nombre del centro urbano Perpignan, conocido por esa industria regional, haya pasado a designar el árbol de que se alimenta la industria: bois de Perpignan y luego simplemente perpignan 'Celtis australis'. El mismo fenómeno ha ocurrido en Italia: en Reggio Emilia, centro urbano donde florece análoga industria regional de mangos de látigo, el árbol es conocido con el nombre de perpignán o palpignán ${ }^{22}$. No menos floreciente parece la misma industria en una tercera región del Mediterráneo occidental, la isla de Cerdeña, donde el nombre del árbol surdzaga etc. 'Celtis australis', de término rural que era en su origen, ha llegado a ser término técnico referido de ordinario a la madera empleada para varios usos. "Il legno di sugargia (o di surdzaga) - nos dice el sardo Salvatore Vacca-Concas ${ }^{23}$ - è molto pregiato per la tenacità

mariane, margiani $=$ Mariana, lodde $=$ Lodde, etc., para lo cual me remito a M. L. WAgner, "Die Bezeichnungen für 'Fuchs' in Sardinien”, ARom, XVI, 1932, págs. 501-514, y La lingua sarda, storia, spirito e forma, Berna, 1950, págs. 298-299.

19 L. Sprtzer, en RIEV, XVI, 1925, pág. 142; $R E W^{3}, 8476 a$.

${ }^{20} \mathrm{~W}$. D. Elcock, De quelques affinités entre l'aragonais et le béarnais, Paris, 1938, pág. 107; y véase $F E W$, II, 2ạ parte (1946), pág. 1226.

${ }^{21}$ Véase también LitTré, s. v.: "L'industrie de Perpignan consiste en fabriques ... de manches de fouets en bois d'alisier nommés perpignans"; y JoAnNe, Dict. géograph. de la France, pág. 1748: "Perpignan, Pyrénées-Orientales, ... grande fabrication de manches de fourche et de fouet en bois de micocoulier".

${ }^{22}$ C. CASAli, I nomi delle piante nel dialetto reggiano, Reggio Em., 1915, págs. 6o y 66; O. Penzig, Flora popol. ital., vol. I, pág. 103; V. Bertold, Questioni di metodo nella linguistica storica, págs. 116,117 y 132.

23 S. VAcca-Concas, Manuale della fauna e della flora popolare sarda, Ca- 
e flessibilità e viene adoperato per fare gioghi e manichi di frusta". Por último, Astigiano concuerda con Provenza en denominar el árbol por medio del vocablo común suria ${ }^{24}$, concordancia que presupone, también en este caso, un hecho de cultura común a las dos regiones, esto es, el florecimiento de la misma industria regional en Provenza y en Piamonte. El elocuente indicio del área alpina occidental de otro nombre del árbol del látigo, fanabrego, etc. Provenza, fava grega Liguria, favagrèa Piamonte ${ }^{25}$, contribuye a afirmar esta deducción en el campo de la historia de la cultura ${ }^{26}$.

Ahora bien, para los fines de una nueva solución del problema etimológico del nombre zurriaga, común al español y al vasco, es notable el hecho de que el adjetivo etnogeográfico $S$ y ri a c a está documentado como elemento de la terminología botánica o agrícola precisamente en el latín de Iberia. Como ya se ha dicho, el adjetivo Sy ri a c a se encuentra en el agrónomo español Columera (XI, III, 16) unido al sustantivo $\mathrm{r}$ a $\mathrm{d}$ ix para indicar una variedad importada de rábano. De fortuna aún mayor parece haber gozado el adjetivo $\mathrm{S}$ y $\mathrm{r}$ i a $\mathrm{ca}$ unido al sustantivo $\mathrm{f}$ a b a para indicar, también en el latín de Iberia (Isidoro, Origines, XVII, vir, 9), el fruto del árbol del látigo. Lo demuestra, además del indicio de la fuente isidoriana, la pujante vitalidad del adjetivo s u ri a ca (=s y riac a) en todo el territorio lingüístico ibero-aquitánico con la función significativa particular de término técnico para indicar, no el árbol del látigo, sino el látigo mismo. En efecto, el completo acuerdo entre el nombre dialectal suryáka 'látigo' de Alós en la región de los Pirineos (Krüger) ${ }^{27}$ y el sinónimo suryák 'látigo' del valle de Arán (Coromines) ${ }^{28}$, confirmado a su vez por el sinónimo souriac difun-

gliari, 1916, pág. 215 ; cf. M. L. WAGner, Historische Lautlehre des Sardischen, Halle, 1941, pág. 242.

${ }^{2+}$ El término piamontés suria 'Celtis australis' de Villanova d'Asti fué recogido por O. Penzig, Flora popol. ital., I, pág. 103; en cuanto al sinónimo provenzal suria 'Celtis australis', cf. H. Schuchardi en $Z R P h$, XXXIV, 1910 , pág. 339. - También se ha desarrollado una industria regional de mangos de látigo hechos con las ramas elásticas del mismo árbol en Taio, lugar de Val di Non (Trentino), a donde fué importada en 1816 (cf. G. Pedrottr e V. Bertoldr, Nomi dialettali delle piante indigene del Trentino, pág. 75).

${ }_{25}^{25}$ Véanse mis Questioni di metodo nella linguistica storica, págs. 132-133.

26 En una investigación que toca, aunque sea indirectamente, la nomenclatura dialectal del "Celtis australis L.", corresponde un lugar de honor a Hugo ScHuchaRd, quien con su acostumbrada y genial penetración ha sido el primero en ver, en la complicada serie de nombres y cruces de nombres, la relación entre los términos geográficos $\mathrm{S}$ y $\mathrm{ria}$ y $\mathrm{S}$ y $\mathrm{riaca}$ y los nombres dialectales del árbol suria Provenza y surdzaga Cerdeña (cf. $Z R P h, \mathrm{XXXIV,} \mathrm{1910,}$ pág. 339, y MEYER-LüBKE, $R E W^{3}, 8501$ y 8502 ).

${ }^{27}$ F. KRüGer, Die Hochpyrenäen (Ländliche Arbeit), en la colección Hamburger Studien zu Volkstum und Kultur der Romanen, XXXII, C/II, 1939, págs. $273-274$.

28 J. Coromines, Vocabulario aranés, Barcelona, 1931, s. v. 
dido en Gascuña (RoHLFs) ${ }^{29}$, no puede interpretarse fácilmente en su justo valor histórico si no se tiene en cuenta el nombre s u r i a c a 'árbol del látigo', documentado para Cerdeña por el Condaghe di San Nicola di Trullas (WAGNer) ${ }^{30}$, donde la denominación botánica $\mathrm{f}$ a b a $\mathrm{S}$ y $\mathrm{r}$ i a c a de la fuente isidoriana aparece ya mutilada del sustantivo $\mathrm{f} a \mathrm{~b} a$, permaneciendo como término rural, mientras que de término rural se transforma en término técnico (suryáka 'látigo' de Alós, etc.) en el territorio dialectal de los Pirineos.

Íntimo contacto, pues, entre la historia de un aspecto de la vegetación de un territorio y la historia de la respectiva industria regional, si se piensa que precisamente en la región de los Pirineos nace y prospera la técnica de los mangos de látigo con Perpignan (perpignán 'árbol del látigo'!) como centro urbano exportador del producto y propulsor de la costumbre.

En la elección del nombre para el producto técnico, para el 'látigo', prevalece, como se ha visto, el tipo de denominación del 'árbol del látigo' que incluye caracteres geográficos (a r b o r S y r i a c a y luego s y ri a ca; bois de Perpignan y luego perpignan), con las consiguientes repercusiones en la economía rural de la región.

Partiendo de estas premisas en el campo de la historia regional de la naturaleza y de la cultura, es verosímil pensar que el nombre del látigo suriaca pudo sufrir en el uso ulterior una innovación debida al intento de los hablantes de evocar el sonido del látigo agitado, y que este intento se confió sobre todo a la geminación de las líquidas (sur- innovado en zurr-). Una vez arraigada en el uso la variante innovada zurriaga, es asimismo verosímil pensar que, gracias a su más vivo simbolismo de los sonidos, pudo naturalmente difundirse, primero al lado de la otra (gasc. sourriac surgido al lado de souriac) y después con detrimento de la otra (cat. surriaque, esp. zurriago, vasc. zurriaga, etc. $)^{31}$. Reducido dentro de los límites de una innovación más tardía, la intención onomatopéyica es bien reconocible en zurriaga; pero innovación que no llega a afectar el elemento derivativo tradicional $-a g a(-\mathrm{a} \mathrm{ca})$, ligado tan tenazmente a todas las variantes. Sería, pues, imprudente reducir la apreciación de zurriaga a la historia de una pura creación onomatopéyica ${ }^{32}$, perdiendo de

${ }^{29} \mathrm{G}$. Rohl.s, Le gascon. Etudes de philologie pyrénéenne, Halle, 1935, págs. 65 y 100.

"M. L. Wagner, Historische Lautlehre des Sardischen, 1941, pág. 242.

s1 Véase S. PAlay, Dict. du béarnais et du gascon modernes, Pau, 1932 (sou. riac, sourriac); respecto a las variantes catalanas surriaques, xurriaques, etc., cf́. $B D C$, XXII, 1934, pág. 226; sobre arag. isordiaca, G. RohlFs, Le gascon, pág. 10o; sobre arag. zurriaga, -o, A. KuHN, "Der hocharagonesische Dialekt", RLiR, XI, 1935, págs. 174 y 183; véase también W. D. Elcock, De quelques affinités entre l'aragonais et le béarnais, pág. 107.

${ }^{32}$ No menos imprudente resulta la interpretación del arag. zuriaca 'látigo' en el seno de la familia latina de corrigia (cf. Elcock, op. cit., pág. 107, 
vista el contorno léxico que revela sus complejas circunstancias expresivas al margen de dos círculos sociales de hablantes, los agricultores que llaman suriaca al 'árbol del látigo' y los carreteros que llaman del mismo modo al 'látigo'.

En este marco histórico se inserta además el episodio representado por la denominación pliniana $\mathrm{fa} b \mathrm{a} \mathrm{Gr}$ a e $\mathrm{ca}$. De hecho, en cuanto sinónimo de siliqua $\mathrm{S}$ y $\mathrm{r}$ i a ca del mismo Puinio (XIV, 103), el nombre f a b a Gra e c a no es sino la variante de un vago motivo geográfico alusivo a tierras lejanas. Se justifica así fácilmente el hecho de que el área lingüística de los reflejos dialectales de $\mathrm{faba}$ G r a e c a (fanabrego, etc. Provenza, favagrèa Piamonte, fava grega Liguria) viene a integrar el área ibero-aquitanosarda de los reflejos dialectales de la denominación gemela ( $\mathrm{f} \mathrm{a} \mathrm{b}$ a) $\mathrm{S}$ y $\mathrm{r}$ i a c a, de modo que, reunidas, las dos áreas se extienden a casi todas las regiones costeras e insulares del Mediterráneo occidental ${ }^{33}$.

Hace tiempo había prometido el presente estudio a Amado Alonso para la hermosa revista que es su iniciativa y su orgullo. Mantengo la promesa como un homenaje lleno de admiración al amigo, ahora que ya no está con nosotros.

VITTORIO BERTOLDI

Roma.

y $F E W$, II, 1946, pág. 1226); véase además A. KuHN, loc. cit. ( * e x c o r $r$ i g i a $t$ a con sustitución de sufijo).

${ }^{\text {sa }}$ Así, pues, en el sector occidental del Mediterráneo se ha verificado una sucesión de imágenes que van del 'árbol empleado en la técnica rural de los látigos' (s y r i a c a) al 'látigo' (s u ri a c a y luego zurriaga), serie expresada por un nombre común al árbol y a su producto, análoga a la que presupone para el sector oriental del Mediterráneo el término técnico $\mu a ́ \sigma \tau \iota \xi$ 'látigo', identificable con $\mu a ́ \sigma \tau \iota \xi$ 'árbol del látigo' (llamado de ordinario por los griegos $\sigma \chi \hat{\imath}$ vos y por los latinos, en razón de la flexibilidad de sus ramas, le n t i s c u s), de donde viene asimismo $\mu a \sigma \tau i ́ \chi \eta$ 'producto resinoso del árbol $\mu a ́ \sigma \tau \iota \xi '$ (cf. Schrader-Nehring, Reallex. indog. Altertumsk., II, 1929, pág. 154). 